\title{
FORMULATION AND OPTIMIZATION OF BUOYANT IN SITU GELLING SYSTEM OF VALSARTAN USING NATURAL POLYMER
}

\author{
S. PRASANTHI'1, M. VIDYAVATHI ${ }^{* 2}$
}

${ }^{1}$ Department of Pharmaceutics, Annamacharya College of Pharmacy, New Boyanapalli, Rajampet 516126, A. P, India, ${ }^{2}$ Institute of Pharmaceutical Technology, Sri Padmavati Mahila Visvavidyalayam, Tirupathi 517502. A. P., India

Email: prasanthiram84@gmail.com

Received: 18 Jun 2017 Revised and Accepted: 31 Aug 2017

\begin{abstract}
Objective: Currently natural polymers have wide spread importance in fabrication of controlled drug delivery systems. Hence in this study ocimum basilicum mucilage, (OBM) a natural polymer used to know its effect as polymer alone and in combination with HPMC K15M and Guargum in oral in
\end{abstract} situ floating gel of Valsartan using 3 full level factorial design.

Methods: FTIR studies conducted to know major drug polymer interactions. OBM, HPMC K15M and Guargum were chosen as three independent variables and examined at 3 levels for in vitro buoyancy $\left(\mathrm{Y}_{1}\right)$ and drug release at $10 \mathrm{~h}\left(\mathrm{Y}_{2}\right)$ as responses. By using mathematical model approach formulation variables were quantitatively evaluated, and optimized formulation (VFIG) subjected for in vitro buoyancy, density, pH, in vitro drug release, drug content, gelling capacity and drug release kinetics. In addition VFIG studied for In vivo buoyancy and release kinetics.

Results: FTIR studies revealed that excipients were compatible with drug. ANOVA results shown that independent variables have significant effect $(\mathrm{p}<0.05)$ on both the responses. Observed responses of optimized formulation ( $3 \%$ OBM, $0.88 \%$ HPMC and $1.25 \%$ Guar gum) were in good agreement with the experimental values. Results of all in vitro evaluations lies within the limits and drug release kinetics followed non-fickian diffusion mechanism. In vivo buoyancy study in rabbit evidenced floatation for $>8 \mathrm{~h}$ and in vivo pharmacokinetic study exhibited increased bioavailability of optimized formulation.

Conclusion: Prepared VFIG with optimized concentrations of OBM, HPMC K15M and Guargum exploiting as a promising dosage form for enhanced gastric delivery.

Keywords: Valsartan, Natural polymers, OBM, In situ floating gel, Buoyancy studies, 3 Level full factorial design

(C) 2017 The Authors. Published by Innovare Academic Sciences Pvt Ltd. This is an open access article under the CC BY license (http://creativecommons.org/licenses/by/4.0/) DOI: http://dx.doi.org/10.22159/ijpps.2017v9i10.20809

\section{INTRODUCTION}

As the oral route account for ease of self-administration and other advantages, most manufacturers prefer to formulate a drug in suitable dosage form for oral delivery. These reasons now attributed for the development of oral drug delivery systems. Drugs which have primary absorption in the stomach region require gastric residence for longer times. Such drugs, if formulated in oral conventional dosage forms fail to reside the drug in gastric region. Hence gastro retentive drug delivery systems have been developed by many approaches [1]. Raft forming system is one of the commonly used approaches for gastric retention of drugs with primary absorption in the stomach region [2]

Valsartan is an angiotensin-II receptor (which is a potent vasoconstrictor), type I antagonist, especially used in hypertension, congestive heart failure and heart attack. Angiotensin-II binding at AT-I receptor is blocked by this drug results in vasodilation which in turn lowers blood pressure [3]. This is a weak acidic drug has absorption window in the acidic environment of stomach [4]. It is rapidly absorbed orally but unfortunately its bioavailability is $23 \%$. Hence number of formulations in the form of solid dispersions [5], $\beta$ cyclodextrin complexes [6], microcapsules [7] etc., have been fabricated by many researchers in order to overcome its low bioavaiability and low solubility. But no attempt has been made to address the retention of valsartan at it's absorption window. So in the present study an attempt was made to develop an in situ gel dosage form to increase the bioavailability of drug by taking the advantage of its primary absorption in the stomach region.

Recently there is a trend in the use of natural polymers in tailoring of drug delivery systems due to added advantages [8]. Hence in this study ocimum basilicum mucilage (OBM) was selected which is an anionic polysaccharide obtained from seeds of ocimum basilicum linn., comprised of glucomannan (43\%) as major fraction and glucan $(2.3 \%)$ as minor fraction $[9,10]$. It's thickening and stabilizing properties have been attributed to offer potential application in this formulation and first time this study conducted to explore it as gelling polymer. In situ solutions undergo phase transition to gel, due to variation in physiochemical properties like change in $\mathrm{pH}$, temperature, ion activation etc., [11]. Main principle involved in this formulation is $\mathrm{pH}$ induced ionic gelation. Sodium citrate complexes with free $\mathrm{Ca}^{2+}$ and maintains the fluidity of in situ gel until it reaches the stomach. Once the formulation reaches the stomach, in the presence of acidic environment $\mathrm{Ca}^{2+}$ get releases and triggers the gelation of OBM. Effervescent agent helps the formulation to float on the gastric contents for extended period [12].

Statistical experimental design involves study of effect of independent variables on dependent variables with least number of experiments and reduces the time required for developmental work [13-16]. OBM elicit gelation in gastric $\mathrm{pH}$ and it's combination with HPMC K15M and guargum postulates durg release retarding power and excellent buoyant properties. The present study aimed at optimization of OBM as gelling polymer alone and in combination with HPMC K15M and guar gum using $3^{3}$ factorial design.

\section{MATERIALS AND METHODS}

\section{Materials}

Valsartan was obtained as a gift sample from Dr. Reddy's labs, Hyderabad, India. Ocimum basilicum seeds were purchased from local market Rajampet, A. P, India. Their species was authenticated by Mrs. N. Uma, Botanist from Government degree college, Rajampet A. P. India. HPMC K15 M was obtained from Vijaya chemicals pvt. Ltd, Pune, India. Calcium carbonate was obtained from Thermo fisher scientific Pvt. Ltd Mumbai; India. Guar gum was obtained from 
Genuine chemicals co., Mumbai, India. Sodium citrate, Sodium bicarbonate were procured from Universal laboratories pvt. Ltd Mumbai, India. All other chemicals used were of pharmaceutical or analytical grade.

\section{Methods}

\section{Extraction of Ocimum basilicum seed mucilage}

Mucilage extraction from ocimum basilicum seeds was carried out by a modified method of Razavi et al. [17] where $100 \mathrm{~g}$ of cleaned ocimum seeds were subjected for soaking in distilled water (at $35{ }^{\circ} \mathrm{C}$ for $12 \mathrm{~h}$ ) seed ratio of $10: 1$ and blended at $1500 \mathrm{rpm}$ for $15 \mathrm{~min}$ to scrap the gum layer off the seed surface. Blended mass allowed to squeeze with the aid of 8 folds of muslin cloth to extract the mucilage. The filtrate was precipitated in the equal amount of the acetone. The precipitated mucilage was separated, dried, milled, packed and kept in dry condition.

\section{FTIR studies}

FTIR studies were conducted to know the compatibility between drug and excipients. In this studies pure valsartan, pure OBM and its mixture with HPMC K15M and guargum were grounded thoroughly with IR grade $\mathrm{KBr}$, then compressed in a hydraulic press at a pressure of $10,000 \mathrm{psig}$, to get a disc. Each disc was scanned over a range of 400-4500 $\mathrm{cm}^{-1}$ using FTIR instrument (FTIR-1600, Shimadzu, Japan). The characteristic peaks were observed and recorded.

\section{Formulation of in situ gel}

Solutions of OBM, guargum, HPMC K15M, were made individually and in combination by the use of deionized water containing $0.05 \% \mathrm{w} / \mathrm{v}$ of sodium citrate and calcium chloride, using magnetic stirrer with constant stirring. These polymer solutions were heated to $60{ }^{\circ} \mathrm{C}$ then allowed to reduce temperatures to $40{ }^{\circ} \mathrm{C}$. Sodium bi carbonate $(0.75$ $\% \mathrm{w} / \mathrm{v}$ ) and valsartan were added and stirring was continued to get an uniform dispersion. Finally sodium benzoate $(0.1 \% \mathrm{w} / \mathrm{v})$ and sucrose $(10 \% \mathrm{w} / \mathrm{v})$ were added and volume was made up to $100 \mathrm{ml}$ [18].

\section{Experimental design}

A three-level, three-factorial $\left(3^{3}\right)$ design chosen for present experimentation using a software DESIGN EXPERT $\AA$ version 8.0.7.1. Independent variables selected were the concentration of HPMC K15M $(A)$, Guar gum $(B)$, and OBM $(C)$. Low $(-1)$, medium $(0)$, and high settings $(+1)$ were the coded factorial levels for three independent variables $[19,20]$. Chosen dependent variables for investigation were floating lag time (in vitro buoyancy) $\left(Y_{1}\right)$, and drug release at $10 \mathrm{~h}\left(Y_{2}\right)$. A total of 27 experimental runs were conducted as shown in table 1 to optimize and analyze the interaction of each level on parameters of formulations. Multiple factorial regression analysis (quadratic model) was carried out to measure the effect of three variables on response $\left(\mathrm{Y}_{\mathrm{i}}\right)$.

$$
\begin{aligned}
Y_{i}=b_{0}+b_{1} A+b_{2} B+ & b_{3} C+b_{4} A B+b_{5} A C+b_{6} B C+b_{7} A^{2}+b_{8} B^{2} \\
& +b_{9} C^{2}(1)
\end{aligned}
$$

Where $Y_{\mathrm{i}-\text { Dependent variable, }}$

$\mathrm{b}_{0}$ - Arithmetic mean response of 27 combinations;

$b_{1}, b_{2}, b_{3} b_{4} b_{5} b_{6} b_{7} b_{8} b_{9}$-Regression coefficients

A, B and C (Main effects) were the average results of changing one factor at a time from its low to high levels by keeping other two constant. $\mathrm{AB}, \mathrm{AC}$ and $\mathrm{BC}$ (Interaction terms) show, how the response changes when two factors are simultaneously changed. $\mathrm{A}^{2}, \mathrm{~B}^{2}$ and $\mathrm{C}^{2}$ (Polynomial terms) were used to investigate nonlinearity.

The significance of three factors and their interactions were evaluated with analysis of variance (ANOVA) and F statistics and $t-$ values were also calculated [21]. 3D response surface plots given visualized observation of how the response parameters affected by independent variables. Desirability approach was employed to locate the optimal settings of the formulation variables to obtain desired response.

Table 1: $3^{3}$ full factorial design of valsartan floating in situ gel

\begin{tabular}{llll}
\hline Coded values & Actual values & & Guar gum (\%) B \\
\cline { 2 - 4 } & HPMC K15M (\%) A & 1.25 & OBM (\%) C \\
\hline High (+1) & 1.50 & 0.63 & 1.75 \\
Medium (0) & 0.75 & 0 & 0.5 \\
Low $(-1)$ & 0 & & 0.5 \\
\hline
\end{tabular}

\section{Evaluation of formulations}

Total 27 formulations were evaluated for following two parameters.

\section{Floating lag time studies for in vitro buoyancy}

Floating lag time was measured in in vitro buoyancy test. USP Type II dissolution test apparatus containing $500 \mathrm{ml}$ of simulated gastric fluid (pH-1.2), with paddle rotation of $50 \mathrm{rpm}$ and $37 \pm 0.5{ }^{\circ} \mathrm{C}$ temperature were selected for this study. Petri plate (diameter 2 inch) containing in situ gelling solution $(10 \mathrm{ml})$ was placed on the surface of the medium and plunged in to the medium with the moving paddle. The time required for the gelled mass to reach surface of the dissolution medium as floating lag time $\left(\mathrm{Y}_{1}\right)$ was noted. This was measured for each formulation in triplicate [22-24].

\section{In vitro drug release studies}

USP type II (paddle type) apparatus was used to know the drug release by providing $50 \mathrm{rpm}$ in $900 \mathrm{ml}$ of simulated gastric fluid $(\mathrm{pH} 1.2)$,at $37 \pm 0.5{ }^{\circ} \mathrm{C}$ temperature. Ten milliliters of in situ gel containing valsartan was transferred to dissolution medium, at predefined time intervals, $1 \mathrm{ml}$ of aliquot was collected, filtered through a $0.45 \mu \mathrm{m}$ membrane filter, suitably diluted and analyzed at $250 \mathrm{~nm}$ by UV spectrophotometer (UV-1800, Shimadzu, Japan). Withdrawn test sample replenished with fresh dissolution medium. All studies were run for a period of $10 \mathrm{~h}$ in triplicate [25-
27] and the amount of drug dissolved at $10^{\text {th }} \mathrm{h}\left(\mathrm{Y}_{2}\right)$ was noted for all 27 formulations.

\section{Preparation of optimized formulation}

Based on the results of above 2 responses of 27 formulations, the optimized concentration for A, B and C were obtained in desirability approach using software DESIGN EXPERT ${ }^{\circledR}$ version 8.0.7.1. Optimized valsartan floating in situ gel (VFIG) was prepared using optimized concentrations of HPMC K15M, guar gum and OBM and evaluated for the responses $\left(\mathrm{Y}_{1}\right.$ and $\left.\mathrm{Y}_{2}\right)$. The values obtained were compared with those predicted by the mathematical model generated, in addition VFIG was also evaluated for $\mathrm{pH}$, density, viscosity, drug content, in vitro gelling capacity, in vivo buoyancy and in vivo pharmacokinetic studies.

\section{Characterization of optimized floating in situ gel}

pH

Determination of $\mathrm{pH}$ for VFIG was carried out by electrometric method by taking adequate volume in a $50 \mathrm{ml}$ beaker using standardized digital $\mathrm{pH}$ meter at room temperature.

\section{In vitro gelling capacity}

Five milliliters of the gelation solution (simulated gastric fluid, $\mathrm{pH}$ 1.2) was taken into a $15 \mathrm{ml}$ test tube maintained $37 \pm 1{ }^{\circ} \mathrm{C}$ temperature and formulation $(1 \mathrm{ml})$ was added slowly to (surface of 
the fluid) the test tube. A stiff gel like structure was formed immediately after formulation comes in contact with gelation solution. The gelling capacity of solution was graded based on the stiffness of formed gel and time period for which the gel retained its rigidity into following three categories [28]. 1. (+) Gels after five min, dispersed within $8 \mathrm{~h} ; 2$. (++) Gels within $60 \mathrm{sec}$. and retains gel structure for $12 \mathrm{~h} . ; 3$. (+++) Gels immediately and retains gel structure for more than $12 \mathrm{~h}$.

\section{Density}

Water displacement method was used to determine the density of the gel formulation. In this study $20 \mathrm{ml}$ of simulated gastric fluid $\mathrm{pH}$ 1.2) was added to $10 \mathrm{ml}$ of in situ solution, to form a gel. So formed gel was weighed after decantation of excess of gastric fluid. The gel was allowed to settle at the base in a $50 \mathrm{ml}$ measuring cylinder. Distilled water was added up to $50 \mathrm{ml}$ marking of measuring cylinder. In presence of gel the volume of water was noted. Amount of water displaced by the gel was calculated from the difference in the volumes of water with and without gel [29].

\section{Determination of viscosity}

Brook field viscometer (DV-ELV) was utilized for viscosity measurement of optimized formulation. The sample aliquot of $50 \mathrm{ml}$ was sheared with speed of spindle $100 \mathrm{rpm}$ at physiological temperature $\left(37^{\circ} \mathrm{C}\right)$. Three replicates were carried out [30].

\section{Drug content}

Ten milliliters of the formulation was added to $900 \mathrm{ml}$ of simulated gastric fluid and stirred for $1 \mathrm{~h}$ on a magnetic stirrer. The solution was filtered, suitably diluted with simulated gastric fluid and the drug concentration was determined by using a UV-visible spectrophotometer (UV-1800 Shimadzu, Kyoto, Japan) at $250 \mathrm{~nm}$ against a suitable blank solution [31].

\section{In vivo floating studies in rabbit}

After getting approval from Institutional Ethics Committee, Sri Padmavathi Women's University (SPMVV), Tirupati, Andhra Pradesh, India (1677/PO/Re/S/2012/CPCSEA/11), the study was employed using $2.5 \mathrm{~kg}$ healthy rabbit which was housed three days and fasted for $12 \mathrm{~h}$ prior to the study but water allowed. An in situ gel prepared by employing $\mathrm{BaSo}_{4}$ as X-ray opaque material (to enable visibility) in place of drug was made to swallow using stomach sonde needle and X-ray photographs of rabbit abdomen were taken at pre identified time intervals of $0,0.5,2$ and $8 \mathrm{~h}$ [32].

\section{In vivo pharmacokinetic studies}

Rabbits with weight of $2.5 \pm 0.5 \mathrm{~kg}$ were selected for the study with $24 \mathrm{~h}$ fasting just before the start of the experiment. Twelve such male rabbits were randomly divided into two groups. Using stomach sonde needle, VFIG and valsartan drug suspension were administered first and second groups respectively at a dose of 03 $\mathrm{mg} / \mathrm{kg}$ body weight of rabbit. At appropriate time intervals $0.5 \mathrm{ml}$ blood samples were collected through ear vein into heparinized tubes. With maintenance of 5,000 rpm for $10 \mathrm{~min}$ using a high-speed centrifuging machine, blood samples were centrifuged and resulting samples were stored at $-18^{\circ} \mathrm{C}$ until analyzed by HPLC [18].

\section{Treatment of plasma samples}

An aliquot of $100 \mu \mathrm{l}$ plasma sample was taken into a RIA® vial, $10 \mu \mathrm{l}$ of $100 \mu \mathrm{g} / \mathrm{ml}$ amilodipine (ISTD (internal standard)) was added, mixed and vortexed for $20 \mathrm{sec}$. A $100 \mu \mathrm{l}$ of $1.5 \% \mathrm{v} / \mathrm{v} \mathrm{HCl}$ was added to this mixture, mixed for $30 \mathrm{sec}$ and $2 \mathrm{ml}$ of ethyl acetate was added. Samples were extracted for $4 \mathrm{~min}$ and centrifuged at 3200 rpm for $4 \mathrm{~min}$. Supernatant $1.6 \mathrm{ml}$ was transferred to evaporation tubes and dried gently under nitrogen gas at $50 \mathrm{C}$ for $12 \mathrm{~min}$ and reconstituted with $500 \mu \mathrm{l}$ of mobile phase and $20 \mu \mathrm{l}$ was injected onto an analytical column to perform the analysis [33].

\section{HPLC analysis}

Chromatographic separation was performed at a flow rate of 1.0 $\mathrm{ml} / \mathrm{min}$, at a wavelength of $272 \mathrm{~nm}$, using an inertsil ODS-3, C18, $(4.6 \times 250 \mathrm{~mm}, 5.0 \mu \mathrm{m})$ column. The column temperature was maintained at $35{ }^{\circ} \mathrm{C}$. The mobile phase was water: acetonitrile: glacial acetic acid (500:500:01). Representative chromatogram has been shown in fig. 5 .

With aid of kinetica software various pharmacokinetic parameters like-maximum plasma concentration $\left(\mathrm{C}_{\max }\right)$, time to reach maximum concentration $\left(\mathrm{T}_{\max }\right)$, area under the plasma concentration-time curve $\left(\mathrm{AUC}_{0 \rightarrow \mathrm{t}}\right.$ and $\left.\mathrm{AUC}_{0 \rightarrow \infty}\right)$, elimination half-life $\left(\mathrm{t}_{1 / 2}\right)$, mean residence time (MRT) and elimination rate constant $\left(\mathrm{K}_{\mathrm{el}}\right)$ etc, were determined.

\section{RESULTS AND DISCUSSION}

\section{FTIR studies}

FTIR spectrum of valsartan (fig. 1(a)) exhibited characteristic peaks at $3286 \mathrm{~cm}^{-1}\left(\mathrm{~N}-\mathrm{H}\right.$ functional group), $3059 \mathrm{~cm}^{-1}$ (Saturated $\mathrm{C}-\mathrm{H}$ group stretching), $2962 \mathrm{~cm}^{-1}$ (Unsaturated $\mathrm{C}-\mathrm{H}$ group stretching), $1728 \mathrm{~cm}^{-1}$ (carboxyl carbonyl),1600 $\mathrm{cm}^{-1}$ (amide carbonyl group). The peak at $1469 \mathrm{~cm}^{-1}$ indicated the presence of $\mathrm{C}=\mathrm{C}$ aromatic group. In the FTIR of OBM (fig. 1[b]) occurrance of peak at the $2958 \mathrm{~cm}^{-1}$ signified C-H stretching of alkyl group. The observed characteristic peak at $3429 \mathrm{~cm}^{-1}$ owing to $\mathrm{OH}$ stretching of alcohol (or water absorbent). Peaks at $1060 \mathrm{~cm}^{-1}$ and at 952 $\mathrm{cm}^{-1}$ were also detected in the present study for $\mathrm{N}-\mathrm{H}$ primary amide and $\mathrm{C}-\mathrm{H}$ aromatic bond respectively. Appearance of characteristic peaks in the physical mixture (fig. 1(c), pure valsartan and polymer OBM indicated the absence of incompatibility between drug and polymers.

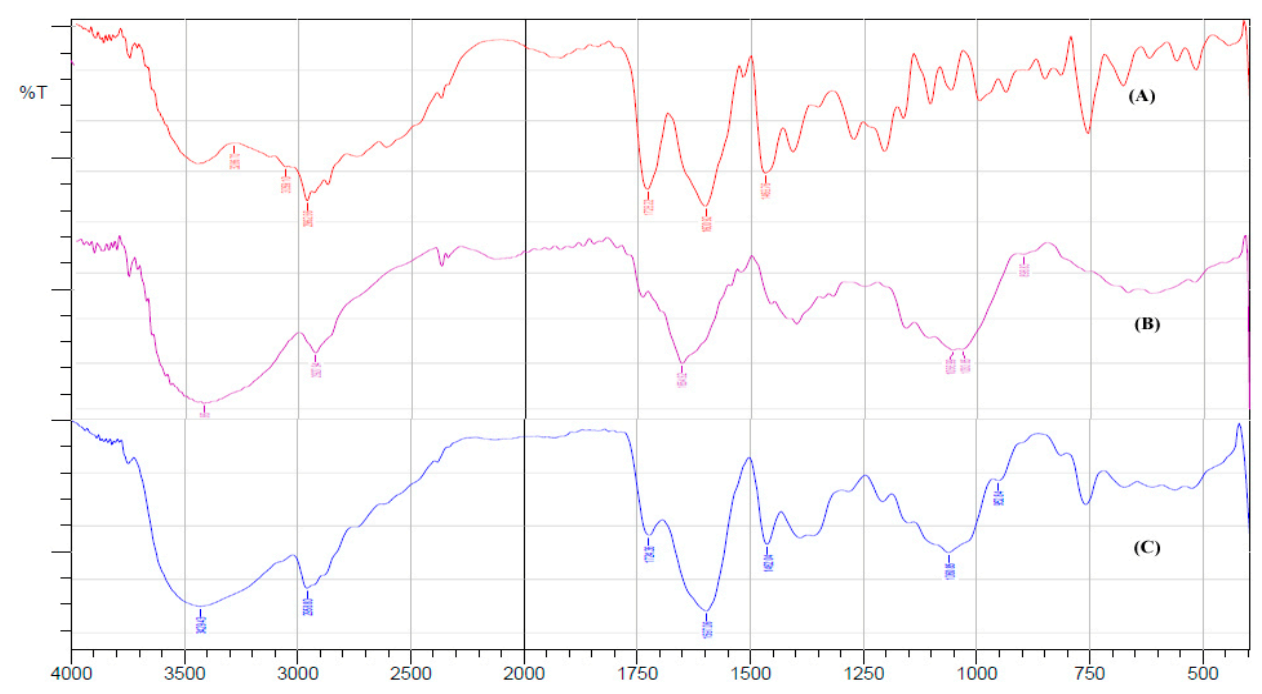

Fig. 1: FTIR spectrum of (A) Valsartan (B) OBM (C) valsartan+polymer mixture 


\section{In vitro buoyancy test}

Measurement of floating lag time (Y1) was carried out for all 27 runs. For response (Y1) a quadratic model was suggested by software on application of factorial design. The Model F-value of 62.00 implied that model was significant. There was only a $0.01 \%$ chance that a large "Model F-Value" could occur due to noise. Values of "Prob $>F$ " less than 0.0500 indicated model terms were significant. In this case A, B, C, AB, A2, C2 were considered as significant model terms due to their $P$ values. P values lesser than 0.1000 indicated, the model terms were significant. The quadratic equation for Y1 was shown in equation (2).

$$
\begin{array}{rl}
Y_{1}=+31.69-21.33 & * A-4.83 * B-4.22 * C+12.17 * A * B+3.17 \\
& * A * C-0.75 * B * C+57.61 * A^{2}+2.44 * B^{2} \\
& +11.27 * C^{2}(2)
\end{array}
$$

Equation (2) prooved that floating lag time decreases with an increase in amount of factor A,factor B and factor C. This was due to high swelling property of the polymers. Similar result was found in gastro retentive matrix tablets of ziprasidone hydrochloride containig HPMC K4M by Sateesha et al. [34]. Combined effect of $A^{*}$ $B$ and $A^{*} C$ were positive but $B^{*} C$ was negative on floating lag time which was exhibited by contour plot and 3D response surface plots (fig. 2).

\section{In vitro drug release at $10 \mathrm{~h}, \mathrm{Q}_{10}\left(\mathrm{Y}_{2}\right)$}

Measurement of drug release at $10 \mathrm{~h}\left(\mathrm{Y}_{2}\right)$ was carried out for all 32 runs. For this response $\left(\mathrm{Y}_{2}\right)$ a quadratic model was suggested by software on application of factorial design. The Model F-value of 395.51 implied that the model was significant. Values of "Prob $>F^{\prime \prime}$
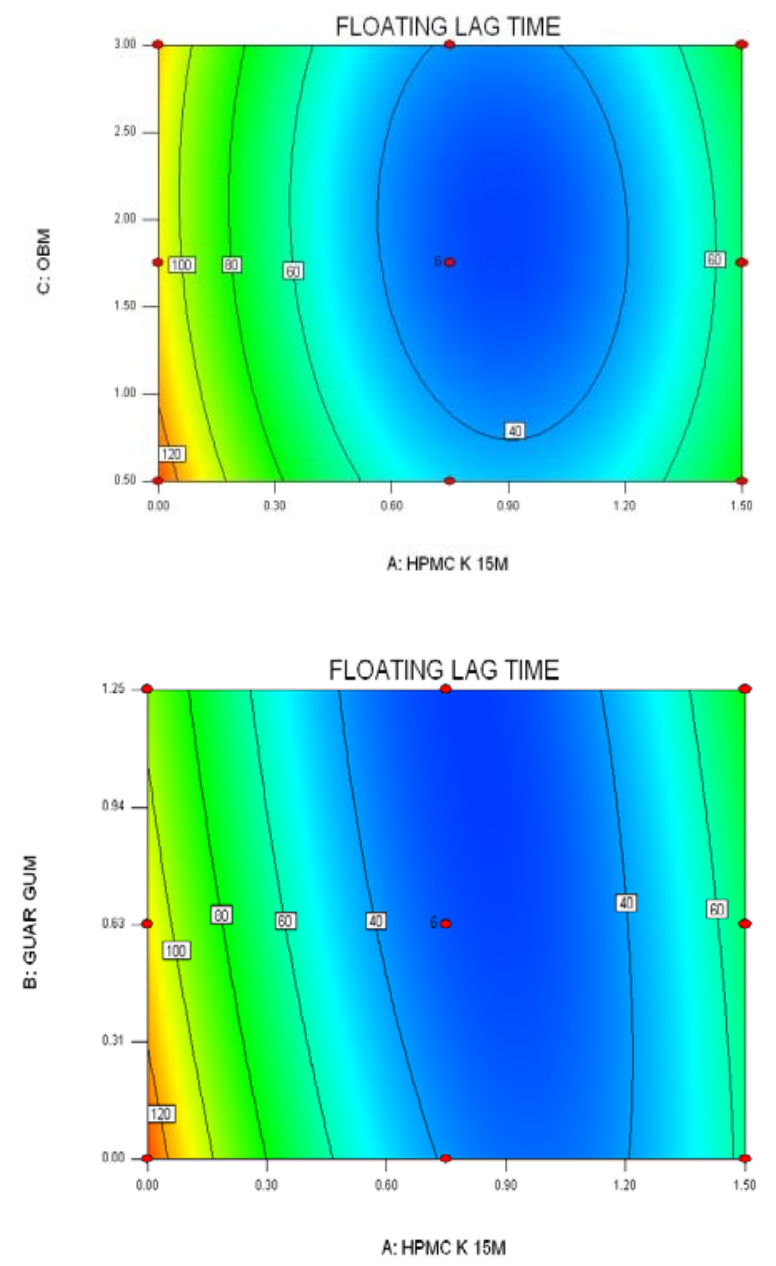

less than 0.0500. indicated that the model terms were significant. In this case $\mathrm{A}, \mathrm{B}, \mathrm{C}, \mathrm{AB}, \mathrm{BC}, \mathrm{C} 2$ were significant model terms. The equation for response $Y_{2}$ was shown in equation (3).

$$
\begin{array}{rl}
Y_{2}=+79.90-3.71 * & A-2.86 * B-11.25 * C-0.81 * A * B-0.28 \\
& * A * C+0.67 * B * C+0.22 * A^{2}+0.44 * B^{2} \\
& +1.86 * C^{2}(3)
\end{array}
$$

Equation (3) prooved that drug release rate appeared to decrease with an increase in amounts of factors A, B, and C. This is in agreement with the literature provided by Rajani et al. [35]. The combined effect of $A^{*} B, A^{*} C$ are negative but $B^{*} C$ is positive on drug release at $10 \mathrm{~h}$ was exhibited by contour plot and 3D response surface plots (fig. 3).

A numerical optimization technique using the desirability approach with Design Expert software was employed to develop optimized formulation with the desired responses. Constraints were set for minimizing floating lag time and drug release at $10 \mathrm{~h}$ to locate the optimum setting of independent variables. Optimized in situ gel formula was arrived by the software which comprised of $3 \% \mathrm{w} / \mathrm{v}$ of OBM, $0.88 \% \mathrm{w} / \mathrm{v}$ of HPMC K15M and $1.25 \% \mathrm{w} / \mathrm{v}$ of Guar gum. The optimized formulation (VFIG) was evaluated for percentage drug release at $10 \mathrm{~h}$, and floating lag time, which were in good correlation with the predicted values as shown in table 2 with desirability of 0.923 . The optimized formulation was further evaluated for parameters like $\mathrm{pH}$, drug content, in vitro gelling capacity, viscosity, density, in vitro drug release kinetics, in vivo buoyancy studies and in vivo pharmacokinetics and results were shown in table 3.
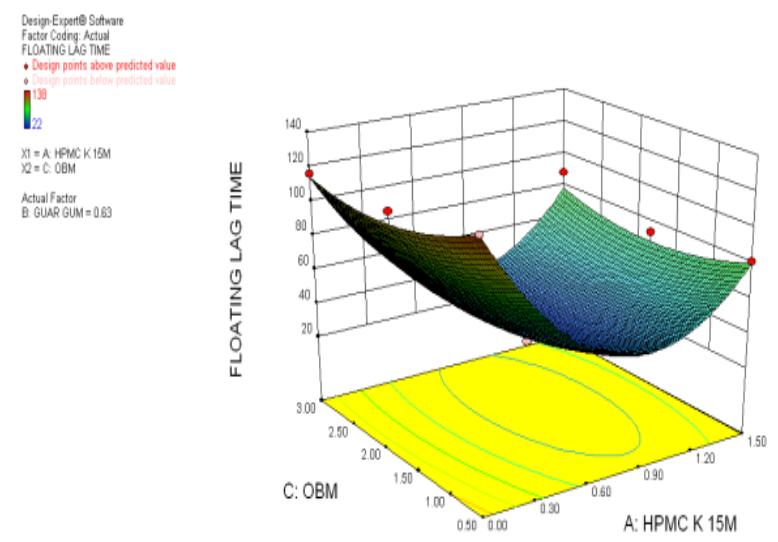

(a)
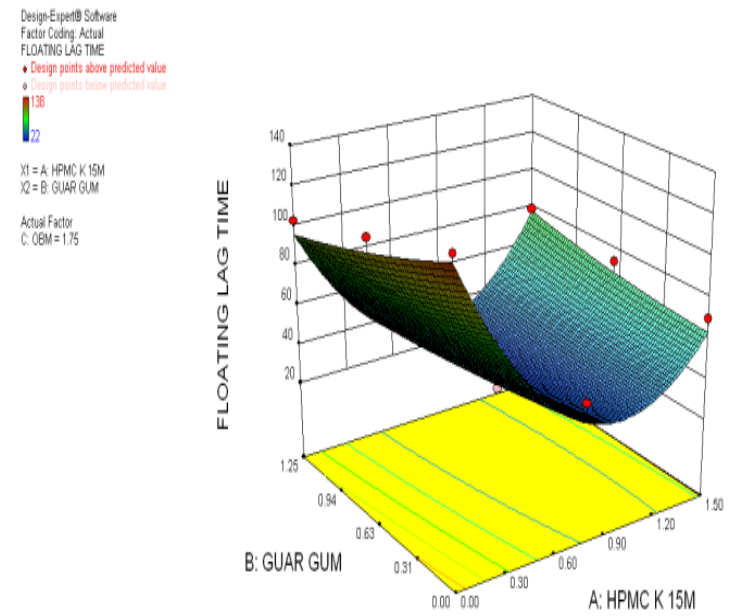

(b) 

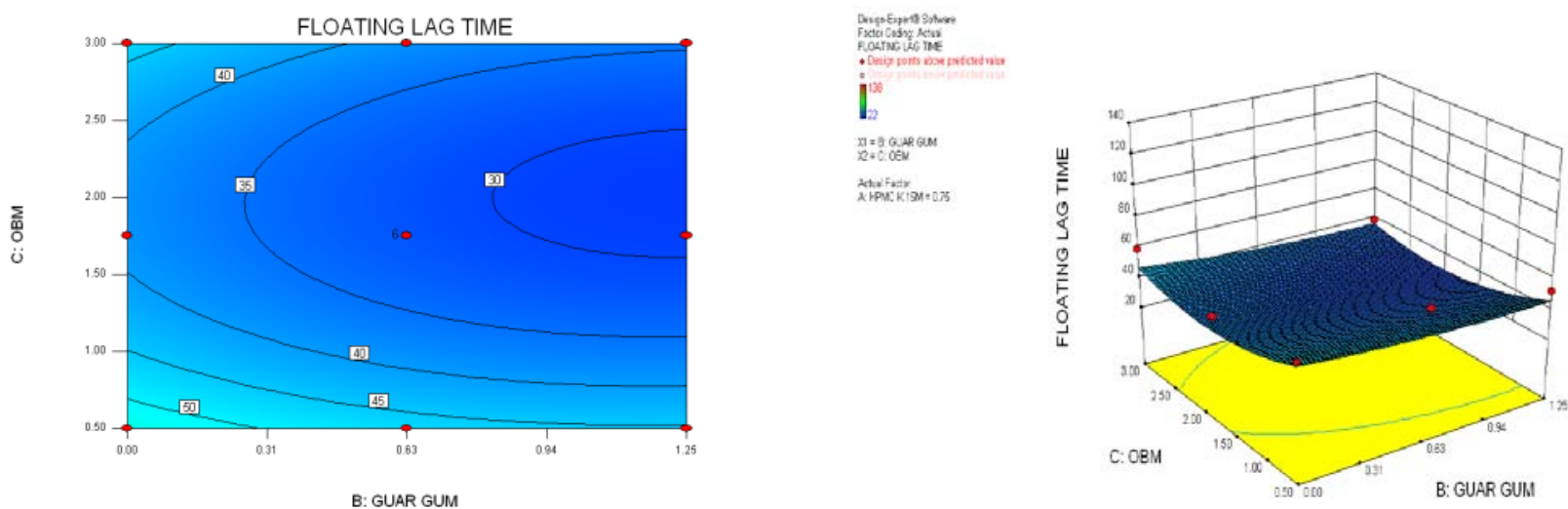

(c)

Fig. 2: Counter plots and response surface plots for (a) effect of $A^{*} C$, (b) effect of $A^{*} B$, (c) effect of $B^{*} C$ on Floating lag time $\left(Y_{1}\right)$
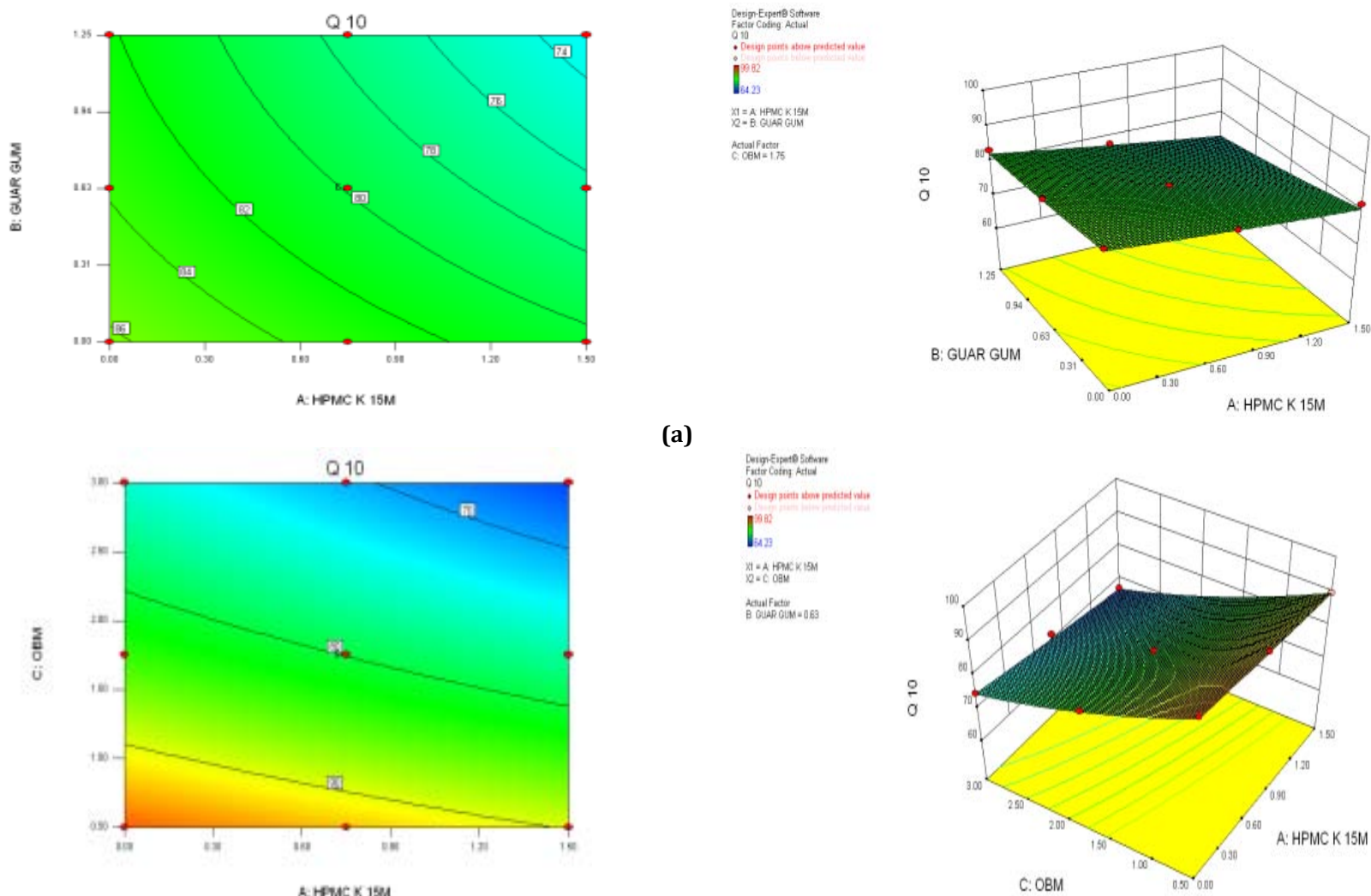

(a)

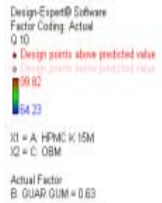

(b)
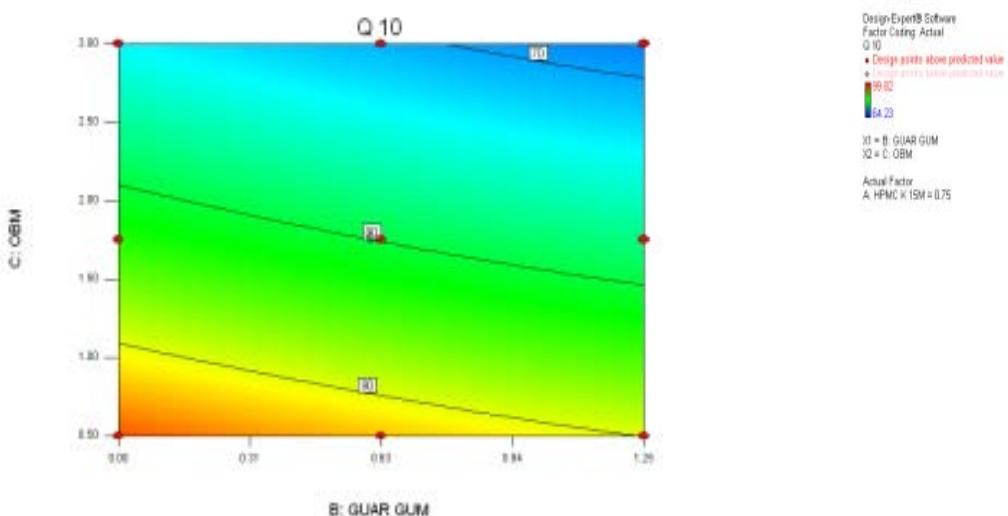

(c)

Fig. 3: Counter plots and response surface plots for (a) effect of $A^{*} B$, (b) effect of $A^{*} C$, (c) effect of $B^{*} C$ on drug release at $10 \mathrm{~h}\left(Y_{2}\right)$ 
Table 2: Comparison between predicted and experimental values for VFIG

\begin{tabular}{lll}
\hline Parameter & Predicted values & Experimental Values \\
\hline 1. Floating lag time $(\mathrm{secs}) \mathrm{Y}_{1}$ & 36.3024 & $36.0021 \pm 0.24$ \\
2. Drug release at $10 \mathrm{~h}\left(\mathrm{Q}_{10}\right) \mathrm{Y}_{2}$ & 67.9226 & $66.9678 \pm 0.2$ \\
\hline
\end{tabular}

Each value represents the mean \pm standard deviation $(n=3)$

\section{Evaluation of optimized formulation}

\section{pH and density}

VFIG was found to have $\mathrm{pH}$ of 6.5 and it was within the acceptable range. It is worthy to note that floating systems must possess density lesser than gastric contents $\left(\sim 1.004 \mathrm{gm} / \mathrm{cm}^{3}\right)$. The measured density of VFIG was $0.869 \mathrm{gm} / \mathrm{cm}^{3}$ (table 3). This less density could contribute to the floatability of VFIG.

\section{Viscosity and drug content}

Optimized formulation was shown viscosity of $339.5 \pm 0.76 \mathrm{cps}$, (table 3) which is suitable for retaining it's gel structure and it was considered to be attributed by optimized concentrations of HPMC K15M and Guargum which was evidenced by counter plots. Significance of viscosity built up in formulations by HPMC K15M and guargum was evidenced by Nanjwade et al. [36] and Alexander et al.
[37] in their individual studies. Insignificant loss of drug during the formulation was evidenced by the result of percent drug content of formulation and it was found to be $99.57 \pm 0.86$ (table 3 ).

\section{In vitro gelling capacity}

Optimized formulation after administration turned out in gel form by formation of 3D-network by complexation with $\mathrm{Ca}^{2+}$ ions and hydrogen bonding with water as a result of consequences of aggregation of the double helical segments this gelling capacity of OBM is evidenced by Yadav et al. in their study [38]. The ascribed grade for gelling capacity of the formulation was (+++), indicating immediate gelation on contact with acidic environment and retains gel structure for more than $12 \mathrm{~h}$. The rigidity of the gel has been citing as a primary factor for controlled release of the formulation since the drug molecules have to infiltrate through the complex network of polymer chains to reach the physiological environment.

Table 3: Results of different parameters of VFIG

\begin{tabular}{lll}
\hline S. No. & Parameter & Values \\
\hline 1. & Floating lag time (Sec.) & $36.0021 \pm 0.24$ \\
2. & $Q_{10}(\%)$ & $66.9678 \pm 0.2$ \\
3. & Density $\left(\mathrm{gm} / \mathrm{cm}^{3}\right)$ & $0.869 \pm 0.1$ \\
4. & Viscosity (cps) & $339.5 \pm 0.76$ \\
5. & Drug content (\%) & $99.57 \pm 0.86$ \\
6. & In vitro gelling capacity & +++ \\
Drug release kinetics & & 0.964 \\
7. & Zero order $\left(\mathrm{R}^{2}\right)$ & 0.963 \\
8. & Higuchi $\left(\mathrm{R}^{2}\right)$ & 0.981 \\
9. & Hixson crowell $\left(\mathrm{R}^{2}\right)$ & 0.991 \\
10. & Korsmeyer peppas $\left(\mathrm{R}^{2}\right)$ & 0.819 \\
11. & Korsmeyer peppas $(\mathrm{n})$ & \\
\hline
\end{tabular}

$(+++)$-Gels immediately and retains gel structure for more than $12 \mathrm{~h}$, Each value represents the mean \pm standard deviation $(\mathrm{n}=3)$

\section{Kinetic modeling of dissolution data}

Optimized formulation (VFIG) drug release data fitted to kinetic modeling. Regression coefficient values evidenced that dissolution data was well fitted to zero order, first order, Higuchi model, Korsmeyer peppas and Hixon-crowell model (table 3). But highest value of regression coefficient $\left(\mathrm{R}^{2}=0.991\right)$ found for Peppas indicated the best fit model the ' $n$ ' value of Peppas was 0.819 . This provided the information of formulation follows non-Fickian release or anomalous diffusion mechanism. This findings confirmed that drug exhibited chain relaxation as well as diffusion mechanisms.

Formulation containing OBM when comes in contact with simulated gastric fluid, calcium chloride brokendown and released free $\mathrm{Ca}^{2+}$ ions that induced gelation due to dimeric association of OBM. Similar dimeric association of OBM with $\mathrm{Ca}^{2+}$ ions was supported by Razavi et al. [39] in their study. As polymer (OBM) being anionic readily cross links with free ca ${ }^{2+i o n s}$ [9]. In addition HPMC K15M and guargum used in the formulation, slowed down the valsartan release and improved residence time of the formulation. Abraham et al. [40] reported drug release retardant potential of guargum in their study and Deng et al. [41] proved drug release retarding efficiency of HPMC K15M.

\section{In vivo buoyancy studies}

X-ray studies were performed on rabbit to check the floating ability of VFIG after oral administration (oral feeding tube was served for administration). The X-ray radiographic images on abdomen were taken at i) Empty stomach, ii) after $0.5 \mathrm{~h}$ of feeding of gel iii) after $2 \mathrm{~h}$ iv) after 8 h. These studies, confirmed that VFIG floated in stomach immediately after administration and continued for nearly $8 \mathrm{~h}$ without any disturbance as shown in fig. 4. It has been speculated that in addition to firm gel formation, floating also a prerequisite for this formulation.

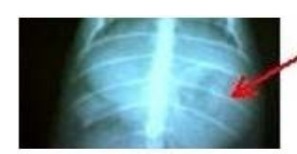

(i)

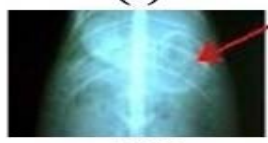

(iii)

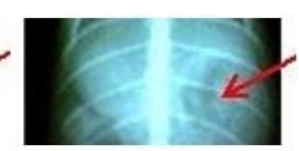

(ii)

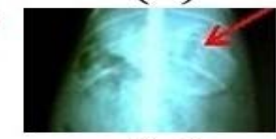

(iv)
Fig. 4: X-ray radiograms showing presence of VFIG in gastric region of rabbit at i) $0 \mathrm{~h}$, ii) $0.5 \mathrm{~h}$,iii) $2 \mathrm{~h}$, iv) $8 \mathrm{~h}$ respectively

\section{In vivo pharmacokinetic studies}

Pharmacokinetic parameters derived from plasma concentration time profile and HPLC chromatogram of valsartan and ISTD were presented in table 4, fig. 5 and 6. Mean pharmacokinetic values 
obtained after plasma analysis of plain drug suspension (standard) and VFIG (test) were as follows: $\mathrm{C}_{\max }, 0.4246$ and $0.483 \mu \mathrm{g} / \mathrm{ml} ; \mathrm{T}_{\max }$ 1 and $12 \mathrm{~h}$; $\mathrm{AUC}_{0-12,} 0.5630$ and $5.998 \mathrm{~h} . \mu \mathrm{g} / \mathrm{ml}$ respectively. In VFIG hike in $\mathrm{T}_{\max }$, elevation in $\mathrm{AUC}_{0-12}$ implied extended release and improved bioavailability of the drug. Although standard formulation reached peak plasma in $1 \mathrm{~h}$, gradually decreased within $2 \mathrm{~h}$, but VFIG attained a peak at $12 \mathrm{~h}$ and decreased gradually, this prolonged plasma concentrations relied on the synergistic effect of polymers. Further, significant increase in AUMC, MRT and $t_{1 / 2}$ with VFIG proven the controlled release of valsartan from in situ gel. This significant differences between pharmacokinetic parameters made this VFIG the best formulation.

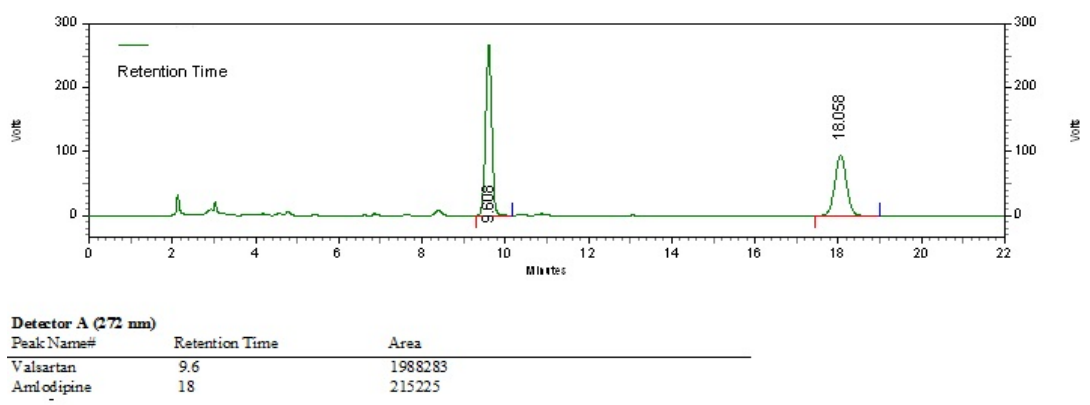

Fig. 5: HPLC Chromatogram of valsartan and ISTD (Amlodipine)

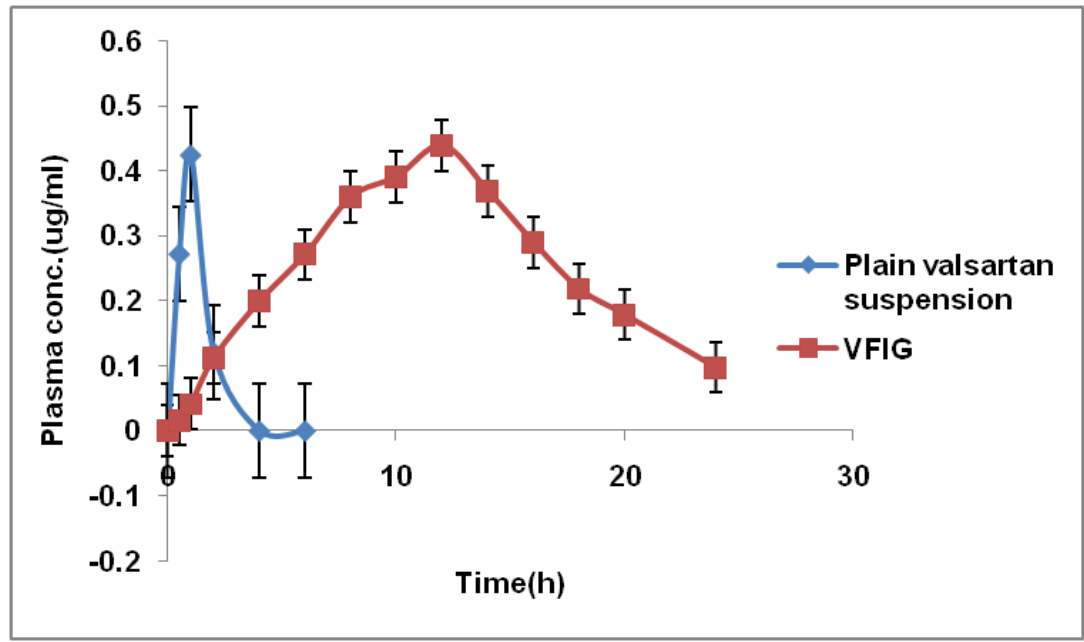

Fig. 6: Plasma concentration time profile of plain valsartan suspension and VFIG $(n=6, \operatorname{mean} \pm$ SD $)$

Table 4: Pharmacokinetic parameters of VFIG (test) and plain drug suspension (Reference) $(n=6, m e a n \pm S D)$

\begin{tabular}{lll}
\hline Pharmacokinetic parameters & VFIG (Test) & Plain drug suspension (Reference) \\
\hline $\mathrm{C}_{\max }(\mu \mathrm{g} / \mathrm{ml})$ & $0.438 \pm 0.42$ & $0.4246 \pm 0.12$ \\
$\mathrm{~T}_{\max }(\mathrm{h})$ & $12 \pm 0.04$ & $1 \pm 0.005$ \\
$\mathrm{AUC}\left(\mu \mathrm{g}^{*} \mathrm{~h} / \mathrm{ml}\right)$ & $5.9987 \pm 1.45$ & $0.5630 \pm 0.04$ \\
$\mathrm{AUMC}\left(\mu \mathrm{g}^{*} \mathrm{~h}^{2} / \mathrm{ml}\right)$ & $72.006 \pm 0.003$ & $0.6548 \pm 0.01$ \\
$\mathrm{MRT}(\mathrm{h})$ & $12.0036 \pm 2.54$ & $1.16292 \pm 0.06$ \\
$\mathrm{~T}_{1 / 2}(\mathrm{~h})$ & $5.1266 \pm 0.68$ & $0.6369 \pm 0.55$ \\
$\mathrm{Cl}(1 / \mathrm{h})$ & $0.4466 \pm 0.88$ & $4.6496 \pm 0.33$ \\
$\mathrm{~V}_{\mathrm{d}}(\mathrm{l})$ & $3.3037 \pm 1.45$ & $4.2725 \pm 0.56$ \\
\hline
\end{tabular}

\section{CONCLUSION}

In this study an improved in situ gel was formed by $\mathrm{pH}$ induced and ionic activation mechanism, in the combination of OBM, Guar gum and HPMC K15M with desirable characteristic features in acidic environment. By application of $3^{3}$ full level factorial design, it was found that the concentration of OBM, HPMC K15M and Guar gum significantly affected the dependent variables like floating lag time $\left(\mathrm{Y}_{1}\right)$ and percent drug released at $10 \mathrm{~h}\left(\mathrm{Y}_{2}\right)$. From findings of the factorial design it was concluded that natural polymer OBM exhibited better drug release in combination with two polymers when compared to alone, and Korsmeyer-Peppas model provided information on drug release from gel structure and indicated diffusion-controlled release. Nonetheless the present work aimed to combine OBM, Guar gum and HPMC K15M, seems to possess sufficient viscosity, increased bioavailability as the gel being present in high amounts at optimized concentrations of polymers. This property could contribute increased diffusion length so that drug release was retarded. This floating oral in situ gel predominantly beneficial for pediatric and geriatric patients and reducing dose frequency.

\section{ACKNOWLEDGEMENT}

The author is thankful for the cooperation and facilities provided by the institute with kind permission of Sri C. Gangi Reddy, Chairman, AITS and Prof. C. Gopinath, Principal, Annamacharya College of pharmacy. The author is also grateful to the Dr. Reddy's labs, Hyderabad, for providing free drug sample of valsartan. 


\section{CONTRIBUTION OF AUTHORS}

Conception and design of work: Prof. M. Vidyavathi

Data collection and analysis: Mrs. S. Prasanthi

Data interpretation: Prof. M. Vidyavathi

Drafting of the article: Mrs. S. Prasanthi

Critical revision of article: Prof. M. Vidyavathi and Mrs. S. Prasanthi

Final approval of the article to publish: Prof. M. Vidyavathi and Mrs. S. Prasanthi

\section{CONFLICT OF INTERESTS}

The authors report no conflict of interest, financial or otherwise

\section{REFERENCES}

1. Saritha C, Shayeda S. Development and characterization of gastroretentive drug delivery system for ritonavir tablets using natural polymers. Asian J Pharm Clin Res 2017;10:318-22.

2. Neha V, Manoj B. Gatro retentive in situ gel formulation-an overview. Int Bull Drug Res 2013;3:69-82.

3. Ahad A, Aqil M, Kohli K, Sultana Y, Mujeeb M, Ali A. Role of novel terpenes in transcutaneous permeation of valsartan: effectiveness and mechanism of action. Drug Dev Ind Pharm 2011;37:583-96.

4. Naveen C, Nalini S, Rama Rao T. Use of the liquisolid compact technique for improvement of the dissolution rate of valsartan. Act Pharma Sin B 2012;2:502-8.

5. Yan YD, Sung JH, Kim KK, Kim DW, Kim JO, Lee BJ, et al. Novel valsartan-loaded solid dispersion with enhanced bioavailability and no crystalline changes. Int J Pharm 2012;422:202-10.

6. Cappello B, Maio Di, Iervolino CM, Miro A. Improvement of solubility and stability of valsartan by hydroxypropyl-betacyclodextrin. J Incl Macrocy Chem 2006;54:289-94.

7. Dong Xun Li, Yi Dong Yan, Dong Hoon Oh, Kwan Yeol Yang, Yoon Gi Seo, Jong Oh Kim, et al. Development of valsartan loaded gelatin microcapsules without crystal change using Hydroxy propyl methyl cellulose as a stabilizer. Drug Delivery 2010;17:322-5.

8. Kharwade RS, More SM, Mahajan UN. Formulation and evaluation of gastroretentive floating tablet using Hibiscus rosa-sinensis mucilage. Asian J Pharm Clin Res 2017;10:444-8.

9. Razavi SMA, Mortazavi SA, Matia-Merino L, Hosseini-Parvar SH, Motamedzadegan A, Khanipour E. Optimization study of gum extraction from basil seeds (Ocimum basilicum linn). Int J Food Sci Technol 2009;44:1755-62.

10. Tharanathan RN, Anjaneyulu YV. Structure of acid stable core polysaccharide derived from the seed mucilage of Ocimum basilicunm linn. Aust J Chem 1975;28:1345-50.

11. Swathi G, Lakshmi PK. Design and optimization of hydrodynamically balanced oral in situ gel of glipizide. J Appl Pharma Sci 2015;5:31-8.

12. Jadhav SL, Benerjee SK. Formulation and evaluation of floating Insitu gel of nizatidine. Int J Res Pharma Sci 2013;4:250-5.

13. Furlanetto S, Cirri M, Maestrelli F, Corti G, Mura P. Study of formulation variables influencing the drug release rate from matrix tablets by experimental design. Eur J Pharm Biopharm 2006;62:77-84.

14. Schwartz JB, O Connor RE. Optimization techniques in pharmaceutical formulation and processing. In: Banker GS, Rhodes CT. editors. Modern pharmaceutics. New York: Marcel Dekker; 1997. p. 727-52.

15. Lewis GA, Mathieu D, Phan-Tan-Luv R. Pharmaceutical experimental design. New York, Marcel Dekker; 1999.

16. Lunstedt T, Seifert E, Abramo L, Thelin R, Nystrom A, Pettersen J. Experimental design and optimization. Chemom Intell Lab Syst 1998;42:3-40.

17. Razavi SMA, Mortazavi SA, Matia-Merino L, Hosseini-Parvar SH, Motamedzadegan A, Khanipour E. Optimization study of gum extraction from basil seeds (Ocimum basilicum linn). Int J Food Sci Technol 2009;44:1755-62.

18. Haoping Xu, Min Shi, Ying liu, Jinling Jiang, Tao Ma. A novel in situ gel formulation of ranitidine for oral sustained delivery. Biomol Ther 2014;22:161-5.
19. Sáskaa Zs, Dredána J, Luhnb O, Balogha E, Slfirra G , Antala I. Evaluation of the impact of mixing speed on the compressibility and compactibility of paracetamol-isomalt containing granules with factorial design. Powder Technol 2011;213:132-40.

20. Singh KS, Dodge J, Durrani MJ, Khan MA. Optimization and characterization of controlled release pellets coated with an experimental latex-I: anionic drug. Int J Pharm 1995;125:243-55.

21. Franz RM, Browne JE, Lewis AR. Experimental design, modeling and optimization strategies for product and process development. In: Lieberman HA, Rieger MM, Banker GS. editors. Pharmaceutical Dosage Forms: Disperse Systems., New York, NY: Marcel Dekker Inc; 1988. p. 427-519.

22. Mushiroda T, Douya RX, Takahara E, Nagata O. The involvement of flavincontaining monooxygenase but not CYP3A4 in metabolism of itopride hydrochloride, a gastroprokinetic agent: comparison with cisapride and mosapride citrate. Drug Metab Dispos 2000;28:1231-7.

23. Kubo W, Miyazaki S, Attwood D. Oral sustained delivery of paracetamol from insitu-gelling gellan and sodium alginate formulations. Int J Pharm 2003;258:55-64.

24. Attwood D, Kubo W, Miyazaki S, Itoh K, Fujiwara M, Tomohiro $\mathrm{H}$, et al. The influence of variation of gastric $\mathrm{pH}$ on the gelation and release characteristics of in situ gelling pectin formulation. Int J Pharm 2006;312:37-42.

25. Higuchi T. Mechanism of sustained action medication, Theoretical analysis of rate release of solid drugs dispersed in solid matrices. J Pharm Sci 1963;52:1145-9.

26. Korsmeyer RW, Gurny R, Doelker E, Buri P, Peppas NA. Mechanisms of solute release from porous hydrophilic polymers. Int J Pharm 1983;15:25-35.

27. Maheswaran A, Padmavathy J, Nandhini V, Saravanan D, Angel P. Formulation and evaluation of floating oral in situ gel of diltiazem hydrochloride. Int J Appl Pharm 2017;9:50-3.

28. Monica RP, Swapnil Uttam S. Controlled release ion sensitive floating oral in situ gel of a prokinetic drug using gellan gum. Indian J Pharm Educ Res 2015;49:158-67.

29. Martin A, James S. Physical chemical principles in the pharmaceutical sciences, physical pharmacy. $3^{\text {rd }}$ ed. Varghese Publishing House, Indian Edition; 1991. p. 513-6.

30. Miteshkumar J, Kanu Patel R, Mukesh Patel R. Strategy for development of $\mathrm{pH}$ triggered floating in situ gel of levetiracetam. Am J Pharm Res 2012;2:828-41.

31. Mahak S, Aarti M, Vishnu Y, Gopkumar P, Sridevi G. Formulation and evaluation of floatable in situ gel for stomachspecific drug delivery of vanlafaxine hydrochloride. Res Rev J Pharm Pharm Sci 2014;3:41-8.

32. Sanjoy Kumar D, Pintu Kumar D, Arnab D, Souvik O, Ronita D, Asish Kumar M, et al. Floating mucoadhesive alginate beads of amoxicillin trihydrate: a facile approach for $\mathrm{H}$. pylori eradication. Int J Biol Macromol 2016;89:622-31.

33. Gonzalez L. Fast screening method for the determination of angiotensin II receptor antagonists in human plasma by highperformance liquid chromatography with fluroimetric detection. J Chromatogr A 2002;949:49-60.

34. Sateesha SB, Rajamma AJ, Yogesha HN. Natural gums as sustained release carriers: development of gastroretentive drug delivery system of ziprasidone HCl. Daru J Pharm Sci 2012;20:2-9.

35. Rajani S, Panna T, Ranendra NS. In vitro and in vivo evaluation of gastroretentive floating drug delivery system of ofloxacin. Asian J Pharm Sci 2013;8:191-8.

36. Nanjwade BK, Adichwal SA, Sutar KP. Development and evaluation of glipizide floating tablet J. Drug Delivery Sci Tech 2012;22:327-33.

37. Alexandar S, Kumar M, Kumudhavalli MV, Umamaheswari D, Jaykar B. Formulation and evaluation of buoyant type of gastro retentive dosage forms of ranolazine tablets. J Pharm Sci Res 2017;9:145-9.

38. Razavi SMA, Rafe1 A. The effect of $\mathrm{pH}$ and calcium ion on rheological behaviour of $\beta$-lactoglobulin-basil seed gum mixed gels. Int J Food Sci Technol 2013;48:1924-31.

39. Yadav AV, Shete AS, Mohite VL. Preparation and evaluation of mucilage of ocimum basilicum as a gelling agent. Res J Pharm Technol 2008;1:201-3. 
40. Abraham TE, George $\mathrm{M}$. Ph sensitive alginate-guar gum hydrogel for the controlled delivery of protein drugs. Int J Pharm 2007;335:123-9.

41. Deng L, Chen J, Zhao Q, Gao B, Ma L, Lian J. Innovative intra gastric ascaridole floating tablets: development optimization and in vitro, in vivo evaluation. Int J Pharm 2015;496:432-9.

\section{How to cite this article}

- S Prasanthi, M Vidyavathi. Formulation and optimization of buoyant in situ gelling system of valsartan using natural polymer. Int J Pharm Pharm Sci 2017;9(10):128-136 